\title{
Chronic idiopathic systemic capillary leak syndrome: a case report
}

\author{
Ahmed M. Alkhunaizi ${ }^{*}$ (D) Abdullah H. Kabbani ${ }^{3}$ and Mohamed A. ElTigani ${ }^{2}$
}

\begin{abstract}
Background: Idiopathic systemic capillary leak syndrome (ISCLS), is a rare disorder characterized by recurrent attacks of varying severity of hypovolemic shock and generalized edema in association with hemoconcentration and hypoalbuminemia in the absence of albuminuria. The chronic form of ISCLS is extremely rare with only a few cases reported in the literature.

Case presentation: Here we report the case of a young woman who developed chronic ISCLS characterized by massive, generalized and persistent edema. The work up confirmed the presence of monoclonal gammopathy. She was treated with several agents with no response.

Conclusion: Chronic ISCLS is a very rare disease of unknown etiology and results in devastating complications. The medical community should be aware of this disease with the hope that targeted therapy will become available in the future.
\end{abstract}

Keywords: Capillary leak syndrome, Clarkson disease

\section{Case}

A 23-year-old female patient who is known to have type 1 diabetes mellitus since the age of 12 years. Her blood sugar had been poorly controlled. She was transferred to our hospital from another institution in April, 2017 for evaluation of anasarca. Two months prior to her admission she started developing generalized body swelling with no associated arthritis, arthralgia or hair loss. There was no family history of similar illness. Her weight was $140 \mathrm{~kg}$. Her weight prior to her illness was around $70 \mathrm{~kg}$. Her exam was significant for massive anasarca involving all extremities, abdominal wall and back. She developed bilateral pleural effusions and pericardial effusion with tamponade. She later on developed bilateral foot drop, adrenal insufficiency, hypothyroidism, acute kidney injury and end stage renal disease (ESRD) (Fig. 1).

\footnotetext{
*Correspondence: aalkhunaizi@gmail.com

${ }^{1}$ Nephrology Section, Internal Medicine Services Division, Johns Hopkins Aramco Healthcare, Saudi Aramco, Box 10955, Dhahran 31311, Saudi

Arabia

Full list of author information is available at the end of the article
}

\section{Laboratory tests}

Admission hemoglobin was $13.7(12.0-16.0) \mathrm{gm} / \mathrm{dL}$. The white blood cell count with differential and platelet counts were normal. Renal function and liver function were normal. Urinalysis showed no proteinuria. Random urine creatinine was $199 \mathrm{mg} / \mathrm{dL}$ and urinary sodium was $8 \mathrm{mmol} / \mathrm{L}$. B-type natriuretic peptide: 18 . Serum albumin was $3.1(3.4-4.7) \mathrm{g} / \mathrm{dL}$. Thyroid stimulating hormone was $5.18(0.35-4.94) \mu \mathrm{IU} / \mathrm{mL}$, free T4: $0.93(0.68-2.53) \mathrm{ng} /$ $\mathrm{dL}$ and free T3: $1.62(1.71-3.71) \mathrm{pg} / \mathrm{mL}$. The chest X-ray showed bilateral pleural effusions. The echocardiogram showed normal ejection fraction greater than $55 \%$ and a large pericardial effusion with impending tamponade. The pleural fluid analysis showed: LDH: $65 \mathrm{U} / \mathrm{L}$, total protein: $2.7 \mathrm{~g} / \mathrm{dL}$ (simultaneous serum sample: protein $5.2(6.3-7.9)$ g/dL, LDH: 133 (120-246) U/L. The antinuclear antibodies were positive at 1:80 with speckled pattern. The anti-double-stranded deoxyribonucleic acid (DNA) was negative. The antibodies to extractable nuclear antigens were all negative. C-reactive protein was 0.8 , and erythrocytes sedimentation rate was $8 \mathrm{~mm} /$ hr. C3:91 (9-180), C4:23 (10-40) $\mathrm{mg} / \mathrm{dL}$ and total serum complements (CH50) were 45 (30-75) U/mL. Hepatitis B, $\mathrm{C}$ and HIV serologies were negative. Tissue glutaminase 


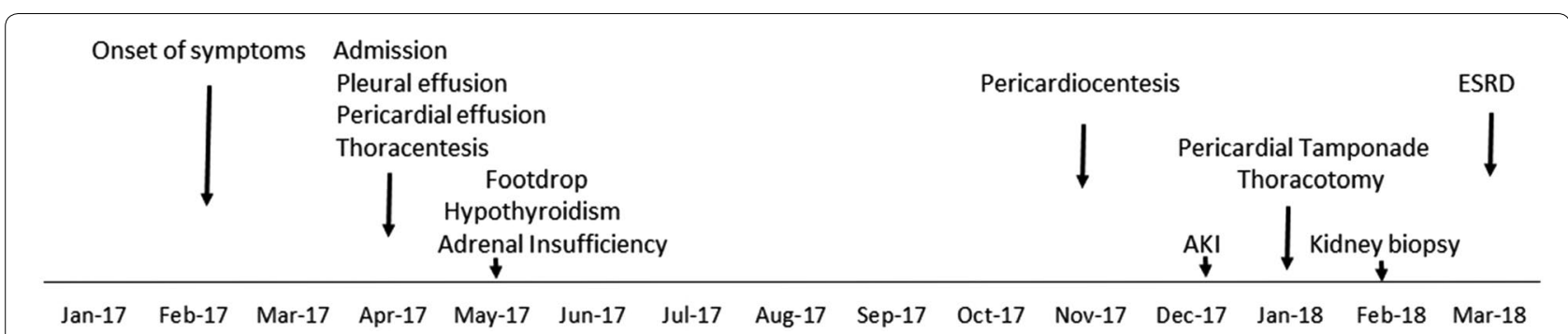

Fig. 1 Timeline of clinical events. AKI acute kidney injury, ESRD end stage renal disease

IgA antibodies were $<1.2 \mathrm{U} / \mathrm{mL}$ (normal $<4.0 \mathrm{U} / \mathrm{mL}$ ). Serum protein electrophoresis showed: total protein 4.9 (6.3-7.9) g/dL, albumin: 2.2 (3.4-4.7) g/dL, alpha-1 globulin: $0.2(0.1-0.3) \mathrm{g} / \mathrm{dL}$, alpha-2 globulin: $0.9(0.6-$ 1.0) $\mathrm{g} / \mathrm{dL}$, beta-globulin: $0.6(0.7-1.2) \mathrm{g} / \mathrm{dL}$, gammaglobulin: $1.0(0.6-1.6) \mathrm{g} / \mathrm{dL}$, albumin/globulin ratio: 0.84 . The serum immunofixation showed small monoclonal IgG kappa within the gamma fraction. Kappa and lambda free light chains were 5.54 and $1.80 \mathrm{mg} / \mathrm{dL}$ respectively. The Kappa/lambda ratio was 3.08. Total IgG: 936 (7671590) $\mathrm{mg} / \mathrm{dL}$, the IgG subclasses: IgG1: 704 (341-894) $\mathrm{mg} / \mathrm{dL}$, IgG2: 66 (171-632) mg/dL, IgG3: 20.9 (18.4-106) $\mathrm{mg} / \mathrm{dL}$, IgG4: $<0.3(2.4-121) \mathrm{mg} / \mathrm{dL}$. C1 esterase inhibitor level was $33(19-37) \mathrm{mg} / \mathrm{dL}$. Total vitamin D was 5.0 (25-80) $\mathrm{ng} / \mathrm{mL}$. Abdominal fat biopsy was negative for amyloid deposition by Congo red stain.

\section{Hospital course}

She required thoracentesis repeatedly to treat the persistent pleural effusion. She also required pericardiocentesis. She was tried on multiple medications that have been shown in earlier case reports to be effective in treating capillary leak syndrome including: high dose systemic corticosteroids, several doses of intravenous immunoglobulins (IVIG) followed by monthly administration for 6 months $(2 \mathrm{gm} / \mathrm{kg}$ body weight), intravenous Theophylline, Terbutaline, Bevacizumab (two doses 2 weeks apart), intravenous methylene blue, and Thalidomide for 4 months. She did not respond to any of these modalities (Table 1).

She had developed recurrent episodes of sepsis related to central line infection and pneumonia and required transfer to the intensive care unit on multiple occasions. She also developed pericardial tamponade and required thoracotomy, pericardial drainage and creation of a large pericardial window. As a result of the septic episodes and the cardiac procedure, she developed acute kidney injury and was started on continuous renal replacement therapy and later was switched to intermittent hemodialysis. After 6 weeks on dialysis, a kidney biopsy was performed and showed acute tubular necrosis with regenerating renal tubules. She however did not recover and became dialysis dependent requiring daily dialysis in an attempt to control the edema. After 24 months of continuous hospitalization with frequent transfers to the step down unit and intensive care unit, she still has massive edema mainly in the lower extremities requiring daily dialysis, is bedbound, and has bilateral foot drop. She has suffered from immobilization hypercalcemia, bone fractures and decubitus ulcerations.

\section{Discussion}

The patient represents a rare case of severe and chronic ISCLS where she developed massive and persistent generalized edema in addition to bilateral pleural effusion and pericardial effusion. The initial laboratory values

Table 1 Therapeutic agents used during the course of illness

\begin{tabular}{llll}
\hline Agent & Dose & Duration & Response \\
\hline Methyl-prednisone & $500 \mathrm{mg} /$ day & Several doses & No \\
IVIG & $2 \mathrm{gm} / \mathrm{kg}$ & Several doses followed by monthly for & No \\
& & 6 months & No \\
Intravenous theophylline & $5 \mathrm{mg} / \mathrm{kg}$ followed by $0.4 \mathrm{mg} / \mathrm{kg} / \mathrm{h}$ & 2 days & No \\
Terbutaline & $5 \mathrm{mg}$ three times/day & 14 days & No \\
Bevacizumab & $5 \mathrm{mg} / \mathrm{kg}$ & 2 doses 2 weeks apart & No \\
Intravenous methylene blue & $2 \mathrm{mg} / \mathrm{kg}$ & One dose & No \\
Thalidomide & $200 \mathrm{mg}$ daily & 4 months & \\
\hline
\end{tabular}

IVIG intravenous immunoglobulins 
were normal except for the presence of monoclonal gammopathy.

The classic systemic capillary leak syndrome is a rare disease of reversible plasma extravasation and vascular collapse accompanied by hemoconcentration and hypoalbuminemia [1, 2]. The first description of the syndrome was by Clarkson et al. who described a case of a 32-year-old woman who experienced "a strange cyclical illness in which she intermittently had a sudden massive movement of plasma from her vascular bed [3]. Typically, patients experience the development of massive edema and shock after a nonspecific prodrome of weakness, fatigue, and myalgias. They may develop ischemiainduced organ failure, rhabdomyolysis, compartment syndromes, and venous thromboembolism. These manifestations may rapidly resolve and patients may experience recurrent and intermittent attacks with spontaneous recovery. Less than 500 cases have been reported in the literature since the initial description by Clarkson et al. [4]. On the other hand the chronic form of ISCLS is extremely rare with only a few cases reported in the literature [5-8]. Unlike the classic form of ISCLS, chronic ISCLS is characterized by persistent edema with no signs of recovery and may be responsive to treatment with systemic steroids and IVIG [5, 7]. Similar to our case, monoclonal gammopathy is classically found in both forms of ISCLS. ISCLS is a life-threatening disorder that carries a high mortality rate. The pathogenesis is poorly understood and is believed to be a manifestation of transient endothelial dysfunction due to endothelial contraction, apoptosis, injury, or a combination of these factors [1]. Exaggerated microvascular endothelial responses to surges of otherwise routinely encountered inflammatory mediators have been also suggested [4]. Certain cytokines were found to be elevated in acute ISCLS sera compared to baseline or sera from healthy controls, including CXCL10, CCL2, IL-1 $\beta$, IL-6, IL-8, IL-12 and tumor necrosis factor $\alpha$ (TNF $\alpha)$ [9].

In severe forms, patients may develop persistent and chronic edema with no sign of recovery. Our patient represents this type of chronic ISCLS where she developed severe and persistent generalized edema and showed no response to any of the modalities that had been previously tried. She also developed hypothyroidism and adrenal insufficiency which may be related to extravasational loss of hormones and their serum binding proteins [10].

The diagnosis of ISCLS is made clinically after excluding conditions that may have a similar presentation such as sepsis, anaphylaxis and angioedema. There is no established treatment for ISCLS and management is mainly supportive directed towards correction of intravascular volume depletion, maintaining organ perfusion, and avoiding severe metabolic acidosis. Crystalloids and or protein containing solutions may be used to maintain hemodynamic stability. Caution must be exercised as excessive fluid administration may lead to worsening edema and development of compartment syndrome. Different modalities have been tried to treat this devastating illness with some success in case reports and case series including vascular endothelial growth factor (VEGF), TNFo, Theophylline, IVIG, Terbutaline and Thalidomide [11-20].

In conclusion, we have described a case of severe chronic ISCLS that has not responded to any modality of treatment. The patient ended up with devastating complications. The medical community should be aware of this disease with the hope that targeted therapy will become available in the future.

\section{Abbreviations}

ISCLS: idiopathic systemic capillary leak syndrome; DNA: deoxyribonucleic acid; IVIG: intravenous immunoglobulins; VEGF: vascular endothelial growth factor; IL: interleukin.

\section{Acknowledgements}

The authors thank Dr. Kirk Druey from National Institute of Allergy and Infectious Diseases, National Institutes of Health, Bethesda, Maryland for reviewing and commenting on the case. Opinions expressed in this article are those of the authors and not necessarily of Johns Hopkins Aramco Healthcare $(\mathrm{JHAH})$. Therapeutic agents used in this case were all off-label.

\section{Authors' contributions}

AMA provided care to the patient, made the diagnosis of ISCLS and did the writing of the manuscript. AHK collected data and helped in caring for the patient. MAET provided medical care to the patient. All authors read and approved the final manuscript.

\section{Funding}

None.

Availability of data and materials

Not applicable.

\section{Ethics approval and consent to participate}

An informed consent was obtained from the patient prior to publication.

\section{Consent for publication}

Approval to publish this case report was obtained by the Institutional Review Board at JHAH.

\section{Competing interests}

The authors declare that they no competing interests.

\section{Author details}

${ }^{1}$ Nephrology Section, Internal Medicine Services Division, Johns Hopkins Aramco Healthcare, Saudi Aramco, Box 10955, Dhahran 31311, Saudi Arabia. ${ }^{2}$ General Internal Medicine, Johns Hopkins Aramco Healthcare, Dhahran, Saudi Arabia. ${ }^{3}$ Faculty of Medicine, Imam Abdulrahman Bin Faisal University, Dammam, Saudi Arabia.

Received: 31 January 2019 Accepted: 18 May 2019

Published online: 28 May 2019 


\section{References}

1. Druey KM, Greipp PR. Narrative review: the systemic capillary leak syndrome. Ann Intern Med. 2010;153(2):90-8.

2. Kapoor P, Greipp PT, Schaefer EW, Mandrekar SJ, Kamal AH, Gonzalez-Paz NC, et al. Idiopathic systemic capillary leak syndrome (Clarkson's disease): the Mayo clinic experience. Mayo Clin Proc. 2010;85(10):905-12.

3. Clarkson B, Thompson D, Horwith M, Luckey EH. Cyclical edema and shock due to increased capillary permeability. Am J Med. 1960:29:193-216.

4. Druey KM, Parikh SM. Idiopathic systemic capillary leak syndrome (Clarkson disease). J Allergy Clin Immunol. 2017;140(3):663-70.

5. Airaghi L, Montori D, Santambrogio L, Miadonna A, Tedeschi A. Chronic systemic capillary leak syndrome. Report of a case and review of the literature. J Intern Med. 2000;247(6):731-5.

6. Bajwa R, Starr J, Daily K. Gemcitabine-induced chronic systemic capillary leak syndrome. BMJ Case Rep. 2017. https://doi.org/10.1136/bcr-2017221068.

7. Mullane R, Langewisch E, Florescu M, Plumb T. Chronic systemic capillary leak syndrome treatment with intravenous immune globulin: case report and review of the literature. Clin Nephrol. 2019:91(1):59-63.

8. Baron D, Mayo A, Kluger Y. Gemcitabine-induced chronic systemic capillary leak syndrome: a life-threatening disease. Clin Oncol (R Coll Radiol). 2006;18(1):90-1.

9. Xie Z, Chan E, Yin Y, Ghosh CC, Wisch L, Nelson C, et al. Inflammatory markers of the systemic capillary leak syndrome (Clarkson Disease). J Clin Cell Immunol. 2014;5:1000213.

10. Then C, Ritzel K, Seibold C, Mann JF, Reincke M. Multiglandular hormone deficiency in a patient with systemic capillary leak syndrome. Case Rep Med. 2015;2015:958283

11. Dowden AM, Rullo OJ, Aziz N, Fasano MB, Chatila T, Ballas ZK. Idiopathic systemic capillary leak syndrome: novel therapy for acute attacks. J Allergy Clin Immunol. 2009;124(5):1111-3.
12. Gousseff M, Arnaud L, Lambert M, Hot A, Hamidou M Duhaut P, et al. The systemic capillary leak syndrome: a case series of 28 patients from a European registry. Ann Intern Med. 2011;154(7):464-71.

13. Hajare KR, Patil P, Bansode J. Idiopathic systemic capillary leak syndrome. Indian J Crit Care Med. 2018;22(5):369-71.

14. Lambert M, Launay D, Hachulla E, Morell-Dubois S, Soland V, Queyrel $\checkmark$, et al. High-dose intravenous immunoglobulins dramatically reverse systemic capillary leak syndrome. Crit Care Med. 2008;36(7):2184-7.

15. de Chambrun PM, Gousseff M, Mauhin W, Lega JC, Lambert M, Riviere $\mathrm{S}$, et al. Intravenous immunoglobulins improve survival in monoclonal gammopathy-associated systemic capillary-leak syndrome. Am J Med. 2017;130(10):1219.

16. Pratesi A, Valoti P, Baldasseroni S, Marchionni N, Tarantini F. Sudden cardiac arrest in a 73-year-old woman caused by systemic capillary leak syndrome. Intern Emerg Med. 2016;11(5):719-20.

17. Staak JO, Glossmann J-P, Esser JM, DiehI V, Mietz H, Josting A. Thalidomide for systemic capillary leak syndrome. Am J Med. 2003;115(4):332-4.

18. Tahirkheli NK, Greipp PR. Treatment of the systemic capillary leak syndrome with terbutaline and theophylline. A case series. Ann Intern Med. 1999:130(11):905-9.

19. Yabe H, Yabe M, Koike T, Shimizu T, Morimoto T, Kato S. Rapid improvement of life-threatening capillary leak syndrome after stem cell transplantation by bevacizumab. Blood. 2010;115(13):2723-4.

20. Umbrello M, Gardinali M, Ottolina D, Zanforlin G, lapichino G. Systemic capillary leak syndrome: is methylene blue the silver bullet? Case Rep Crit Care. 2014;2014:141670

\section{Publisher's Note}

Springer Nature remains neutral with regard to jurisdictional claims in published maps and institutional affiliations.
Ready to submit your research? Choose BMC and benefit from:

- fast, convenient online submission

- thorough peer review by experienced researchers in your field

- rapid publication on acceptance

- support for research data, including large and complex data types

- gold Open Access which fosters wider collaboration and increased citations

- maximum visibility for your research: over $100 \mathrm{M}$ website views per year

At $\mathrm{BMC}$, research is always in progress.

Learn more biomedcentral.com/submissions 